\title{
SHS PROCESSING OF CYCLONE FERROSILICIUM DUST
}

\author{
M. Kh. Ziatdinov' ${ }^{1}$, I. M. Shatokhin², I. R. Manashev ${ }^{3}$ \\ 1 Tomsk State University (Tomsk, Russia) \\ 2 NTPF "Etalon" (Magnitogorsk, Russia) \\ ${ }^{3}$ Nosov Magnitogorsk State Technical University (Magnitogorsk, Russia)
}

E-mail: ziatdinovm@mail.ru; mir@ntpf-etalon.ru

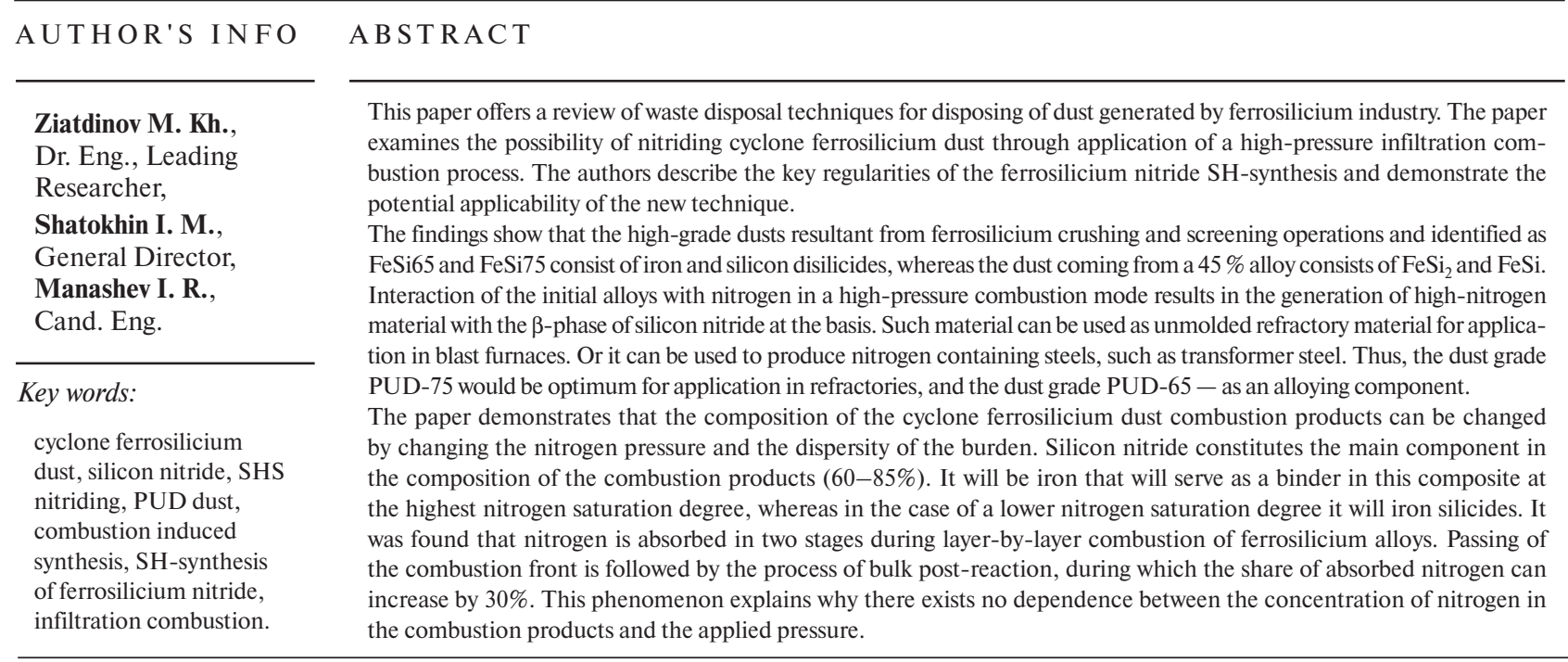

\section{Introduction}

Ferrosilicium industry generates a great amount of wastes, the total quantity of which exceeds the actual output of ferrosilicium by three times [1]. A part of the wastes (e.g. quartzite, coke, coal and slag) gets disposed of serving as commodities for construction and steel industries. The dry dust from gas scrubbers (microsilica) is an essential component of refractory concretes. Ferrosilicium crushing dust, as well as dust resultant from crushing other ferroalloys, belongs to the category of wastes that are not easily marketable. Entrapped with the scrubber bag filters, such dust particles are the result of ferrosilicium crushing and screening. The aspiration system is capable of entrapping up to 3-8\% of dust particles of ferrosilicium and other ferroalloys [2]. Dust generated in the process of ferrosilicium crushing is the result of separation of various proeutectoid constituents due to the presence of impurities, as well as the following phase transition occurring at the temperature of $918^{\circ} \mathrm{C}: \mathrm{FeSi}_{2,3} \rightarrow \mathrm{FeSi}_{2}+\mathrm{Si}$. Such eutectoid transformation of leboite into silicon disilicide results in a bigger volume of the alloy and its decomposition [3].

A conventional disposal technique for cyclone ferrosilicium dust includes briquetting. However, it is not an efficient technique as the resultant briquets have low density and the silicon absorption degree is low. Besides, the binder used in briquetting brings non-metallic inclusions into steel ingots. That's why the processing techniques that help convert silicon-containing waste into materials containing silicon-nitrogen compounds are considered more advanced. Compositions with silicon oxynitrides, silicon nitrides and sialons are widely used in refractory materials [4].

The paper [5] describes the possibility to use a furnace for processing silicon-containing wastes resultant from the production of titanium and magnesium and containing $62.2 \% \mathrm{Si}, 2.3 \% \mathrm{Fe}, 1.1 \% \mathrm{Al}, 1.13 \% \mathrm{Ti}, 1.25 \%$ $\mathrm{Ca}, 13.9 \% \mathrm{O}, 12.3 \% \mathrm{Cl}$. The products of such processing contain the nitrides $\alpha-\mathrm{Si}_{3} \mathrm{~N}_{4}$ and $\beta-\mathrm{Si}_{3} \mathrm{~N}_{4}$, as well as the oxynitride $\mathrm{Si}_{2} \mathrm{~N}_{2} \mathrm{O}$.

The papers $[6,7]$ describe a disposal technique for disposing of silicon-containing sludge, the waste of monocrystal processing, by burning it in nitrogen atmosphere. Silicon and aluminium powders are added to dry sludge to improve its exothermicity. The resultant product, which contains sialon, can be used in the refractories production.

Silicon nitride is one of the few oxygen-free high-melting compounds extensively utilized in numerous production processes. This applicability is due to certain unique physical and chemical properties of silicon nitride and compositions with it. The maximum amount of materials with silicon nitride are used for the production of refractories for various applications. Baked refractories containing silicon nitride are used in aluminium smelters, blast furnaces, waste recycling equipment and ceramic kilns and other machines that require maximum heat-resistance.

Production of unformed materials for blast furnaces remains an important application for silicon nitride containing refractories. The silicon nitride used in the refrac- 
tories for tap holes and chutes is introduced in the form of ferrosilicium pre-saturated with nitrogen (ferrosilicium nitride) $[8,9]$. Such nitrided ferrosilicium is critical for the production of nitride inhibited transformer steel and steels with a superequilibrium concentration of nitrogen $[10,11]$.

The paper [12] describes an advanced ferrosilicium nitride production process adopted by a FESIL LILLEY plant in Trondheim, Norway. $\sim 2$ tons of cyclone ferrosilicium (silicon) dust are charged in vertical cylindrical resistance furnaces. The furnace is then sealed and filled with nitrogen. A slow heating process takes place aimed at creating a uniform temperature field throughout the burden. Heating continues until nitrides start forming in the powder. At this point the power is disabled, and the temperature regime is maintained due to the exothermicity of the $\mathrm{Si}_{3} \mathrm{~N}_{4}$ formation reaction. The process temperature can be regulated by changing the nitrogen feed rate. A complete nitriding cycle takes $3-4$ full days depending on the initial material used. In that time the weight of the burden rises to $\sim 3$ tons. The resultant product contains over $30 \% \mathrm{~N}$. The advantage of this process is in the fact that the furnace is fed a considerable amount of material at once (up to 2 tons). At the same time, it has its drawbacks. It takes a considerable processing time (up to 100 hours) when a relatively low and almost constant temperature $\left(\sim 1,200{ }^{\circ} \mathrm{C}\right)$ need to be maintained. It is necessary so that the temperature did not exceed the ferrosilicium melting point and so that the nitriding process developed as a solid phase process. Reaching the melting point results in a drastic drop in burden permeability; at the same time, the nitride saturation process slows down and can completely stop. During such solid phase nitriding, the baking processes develop extremely slowly resulting in a fine dispersed dust. It may not be easy to further use such dust as a nitrogen-containing addition alloy.

The papers [13-15] examine certain regularities of the silicon-in-nitrogen burning process and explore how silicon nitride is formed, while the paper [16] demonstrates that the SHS nitriding process can actually be applied to the standard ferrosilicium grades. The authors look at alloys of different compositions to understand certain regularities in how they burn. The paper [17] describes how MXene $(\mathrm{Fe}, \mathrm{Ti})_{3} \mathrm{AlSiC}_{2}$ with $90 \mathrm{wt} \%$ of the master phase can be produced by SHS from the mixtures of ferrosilicium, soot, titanium and aluminium.

This paper describes the results of an experimental study in which nitrided ferrosilicium was produced by SHS and dust resultant from crushing and screening of ferrosilicium or cyclone dust was used as the initial material.

\section{Initial Materials and Methods of Research}

Cyclone dust is basically small particles of ferrosilicium that form as a result of its crushing and screening and get accumulated in dust collectors (Fig. 1). Tables 1 and 2 describe the chemical and phase composition of such dust (i.e. the product of crushing and screening operations)

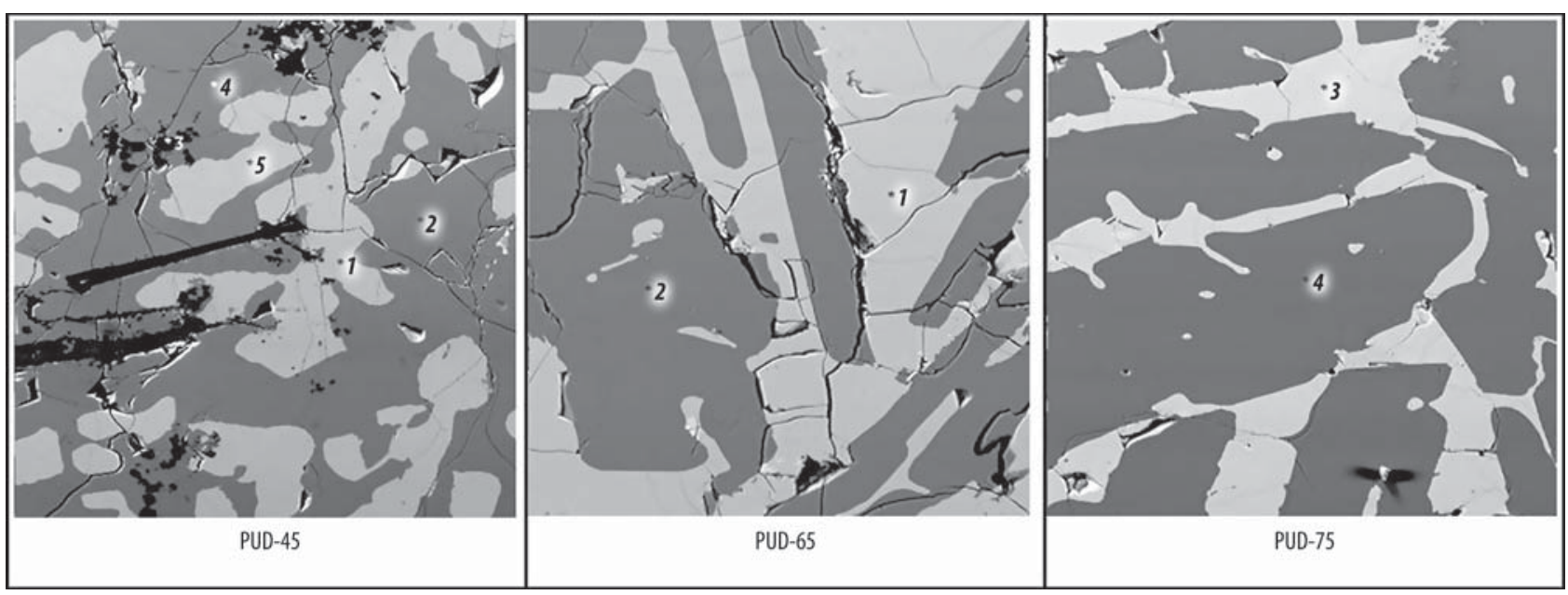

Fig. 1. Ferrosilicium crushing and screening dust microstructure, $\times \mathbf{2 0 0}$ 
which was used for the purposes of this research study. All alloys are dual-phase alloys.

The process of SHS processing of cyclone ferrosilicium dust was studied using a laboratory-scale high-pressure SHS reactor with the capacity of 3 liters. The reactor has sight glasses made of quartz glass through which one can monitor and take a video of the process. The unit is also equipped with $\mathrm{W} / \mathrm{Re}$ thermocouples which enable to continuously monitor the combustion temperature and keep a computer temperature profile log. The cyclone ferrosilicium dust was nitrided in a combustion mode in gas-permeable cylinders made of steel mesh. The cylinders have a diameter of $5 \mathrm{~cm}$ and a height of $7 \mathrm{~cm}$. X-ray spectral microanalysis of specimens before and after burning was carried out with the help of a sequential X-ray fluorescence spectrometer XRF-1800. Phase analysis of the initial powders and the combustion products was carried out with the help of an X-ray diffractometer XRD 6000 by Shimadzu.

\section{Results of experiments}

Synthesis of silicon nitrides generates a considerable amount of heat: $\mathbf{3 S i}+\mathbf{2} \mathbf{N}_{\mathbf{2}} \rightarrow \mathbf{S i}_{3} \mathbf{N}_{\mathbf{4}}+\mathbf{1 7 9 . 0} \mathrm{kcal} / \mathbf{m o l}$. Due to this, synthesis of $\mathrm{Si}_{3} \mathrm{~N}_{4}$ can be realized as an infiltration combustion process [13-15]. The calculated adiabatic combustion temperature of the silicon nitriding process can exceed $4,000^{\circ} \mathrm{C}$. At the same time, the actual heating temperature experimentally measured with thermocouples is $1,900-2,200^{\circ} \mathrm{C}$. At the nitrogen pressures used in the experiment, these temperatures are close to the temperature at which silicon nitride starts to decompose.

The adiabatic nitrogen combustion temperature for ferrosilicium alloys $(\mathrm{Fe}-\mathrm{Si})$ will be lower since the reaction between iron and nitrogen only generates slight heat and iron nitrides that form as a result do not have thermal stability. Besides, the $\mathrm{Si}$ and $\mathrm{Fe}$ are present in ferrosilicium as thermally stable silicides. The paper [18] describes the calculated values of the adiabatic nitrogen combustion temperatures $\left(T_{\mathrm{ad}}\right)$ for silicon-iron alloys. These values were used to analyze the adiabatic combustion temperatures of the grades PUD-45, PUD-65, PUD-75 used in the experiments (see Table 1). As the theoretical combustion temperatures for alloys with different concentrations of silicon are quite high, it can be expected that $\mathrm{SH}$-synthesis in the ferrosilicium-nitrogen system is possible within a broad range of compositions of ferrosilicium alloys.

Ferrosilicium nitriding, just like silicon nitriding, is an infiltration combustion process. It is due to the differential nitrogen pressure in the combustion zone and in the environment that a nitrogen filtering effect is created and constantly maintained. Pressure dropping in the reaction zone is the result of ferrosilicium constantly absorbing the reactant gas as the temperature rises. That's why the differentiating feature of the infiltration combustion process is that it is influenced by such parameters of the reacting mixture that define its filtration conditions, and namely, burden porosity, nitrogen pressure, particle size, the size of the burden sample [16; 19-20].

In its original state, the entrapped product of ferrosilicium crushing and screening operations is a powder, $90 \mathrm{wt} \%$ of particles in which are smaller than $140 \mu \mathrm{m}\left(\delta_{50} \approx 50 \mu \mathrm{m}\right)$. Cyclone dust of that size can be nitrided in combustion mode only when the concentration of silicon is maximum (PUD-75 grade). To make alloys with lower concentrations of silicon combustible in nitrogen, they were pre-ground. Finer cyclone dust powders were obtained with the help of an air circulation unit of the K-05 type [21]. Fig. 2 shows dependences between combustion temperature and rate for burning cyclone dust of different grades of ferrosilicium in nitrogen, as well as the nitrogen concentration in the final product. It also shows how the silicon-to-nitride transformation rate in the processed powders is dictated by the nitrogen pressure. A higher nitrogen pressure leads to a significantly higher combustion rate of ferrosilicium alloys irrespective of the grade. The combustion temperature also sees a significant rise. Higher concentrations of silicon in the initial alloys are associated with higher
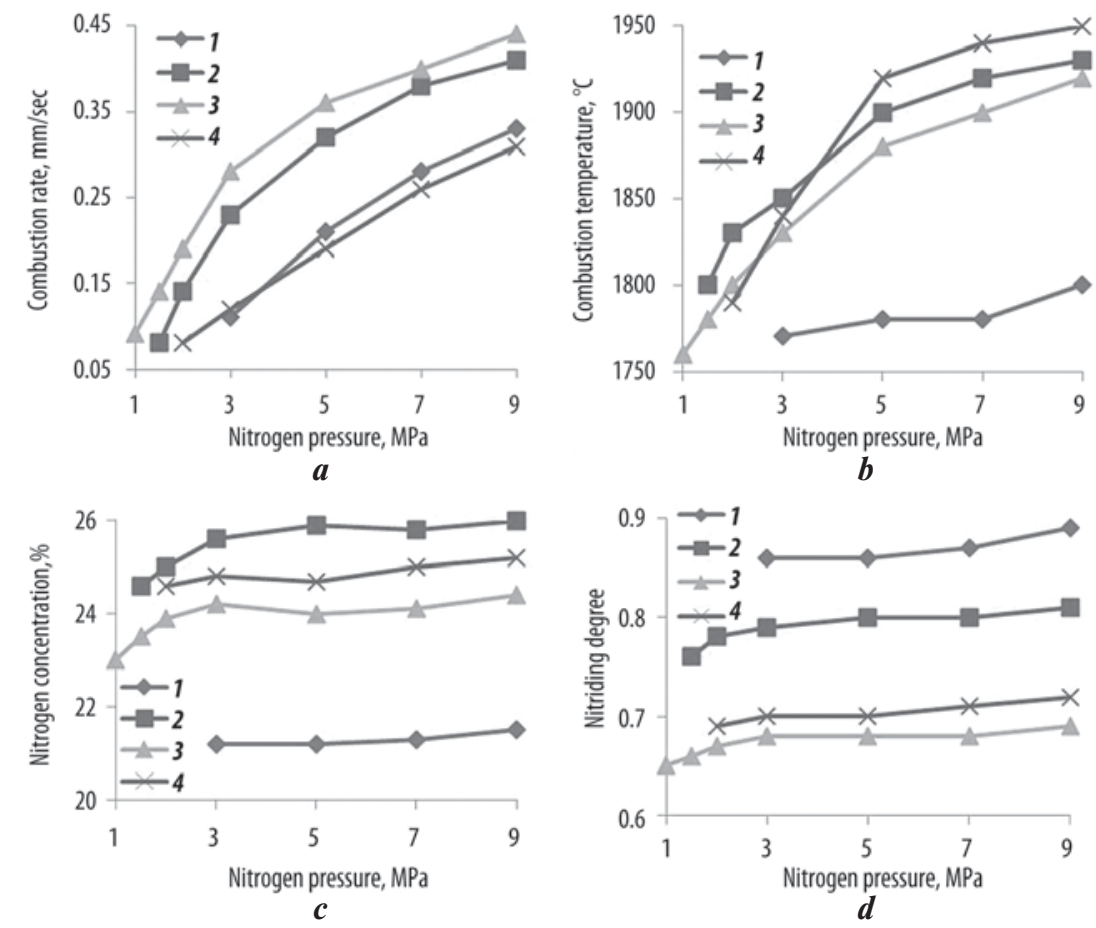

Fig. 2. How nitrogen pressure influences the combustion rate (a) and temperature (b), nitrogen concentration $(c)$ and the nitriding degree $(d)$ of cyclone ferrosilicium dust:

1 - PUD-45; 2 - PUD-65; 3 - PUD-75; dispersity $\delta_{50} \approx 15 \mu \mathrm{m}$ $(\leq 30 \mu \mathrm{m}) ; 4-$ PUD-75 initial $\delta_{50} \approx 50 \mu \mathrm{m}(\leq 140 \mu \mathrm{m})$ 
combustion rate and temperature within the entire range of nitrogen pressures used. At the same time, the concentration of nitrogen in the combustion product and the silicon-to-nitride transformation rate see slight changes only.

An X-ray phase analysis of the products synthesized by burning ferrosilicium alloys in nitrogen shows that the predominant phase in all the studied variation ranges of initial parameters includes the $\beta$-phase of silicon nitride. No significant amounts of the $\alpha$-phase of silicon nitride were detected.

\section{Discussion}

The calculations show that the pores of the ferrosilicium burden do not have enough reactant gas to sustain combustion. That's why the major amount of nitrogen is delivered to the infiltration combustion wave from around the reactor. Such infiltration is created and maintained due to the pressure gradient in the reaction zone and beyond the burden, which is the result of a chemical reaction when nitrogen is constantly absorbed, and the pressure is dropping. The combustion zone acts as a chemical pump supplying gas to the nitride formation zone. The porosity of the cyclone ferrosilicium dust burden that has not been packed is $60-70 \%$. In this case, as the calculations indicate, to achieve a $100 \%$ silicon-to-nitride conversion due to the nitrogen inside the pores only, the pressure in the reactor should be $\sim 100 \mathrm{MPa}$. Consequently, the higher the nitrogen pressure is, the easier it is delivered into the reaction zone, the higher the heat generation rate is. This, in turn, leads to a higher temperature in the combustion zone resulting in a rising combustion rate.

The fact that the concentration of nitrogen in the synthesized product does not depend on the pressure is attributed to that nitrogen is absorbed in stages during combustion. An earlier research study of the ferrovanadium combustion process revealed that the staged process of nitrogen saturation is determined by the physical state of the synthesized product past the combustion wave [18]. Thus, when refractory components prevail in the combustion products, they retain their gas permeability, therefore the nitrogen saturation process may continue even past the reaction wave in a bulk post-reaction mode. Analysis of the microstructure of the sample combustion products shows that all of the products remain highly gas permeable (Fig. 3). That's why an intensive nitrogen absorption can be possible even past the combustion wave.

To determine the share of such post-reaction in the total amount of nitrogen in synthesized products, the combustion process would be interrupted by dumping the pressure from the reactor and filling it with inert argon. Nitrogen concentration was analyzed in the specimens, and the analysis showed that post-nitriding results in a significantly increased nitrogen concentration. In this bulk post-reaction mode, after the layer-by-layer combustion front has been passed, the share of absorbed nitrogen may be as high as $30 \%$. The post-nitriding stage offsets the effect of the nitrogen pressure on the nitrogen concentration in the synthesized products.

A feature distinguishing the cyclone ferrosilicium dust combustion products is that the volume concentration of nitrides in them exceeds $90 \%$. It can primarily be attributed to a high concentration of silicon in the initial ferrosilicium. And a great difference in density between silicon and iron adds to it. Iron can be found throughout the material as separate areas of up to $\sim 100 \mu \mathrm{m}$ (see Fig. 3). Such metallic inclusions probably form as a result of merging ferrosilicium melt, which is formed when nitrides are produced during combustion. Such iron-containing formations are evenly distributed throughout the combustion product.

The actual absence of $\alpha-\mathrm{Si}_{3} \mathrm{~N}_{4}$ in the combustion products is linked to the fact that a nitride with that crystal structure retains stability till the temperature reaches $\sim 1,400{ }^{\circ} \mathrm{C}$, and if the temperature continues to rise, it transforms into the $\beta$-phase. In the case of silicon nitride, this phase transformation is irreversible. The registered nitrogen combustion temperature of ferrosilicium dust of different compositions is higher than $1,750{ }^{\circ} \mathrm{C}$ at all studied nitrogen pressures.

The phase composition of the nitrided ferrosilicium is mainly governed by the $\mathrm{Si} \rightarrow \mathrm{Si}_{3} \mathrm{~N}_{4}$ transformation degree. If the transformation degree is maximum, it results in a dual-phase product that consists of beta-nitride and iron.

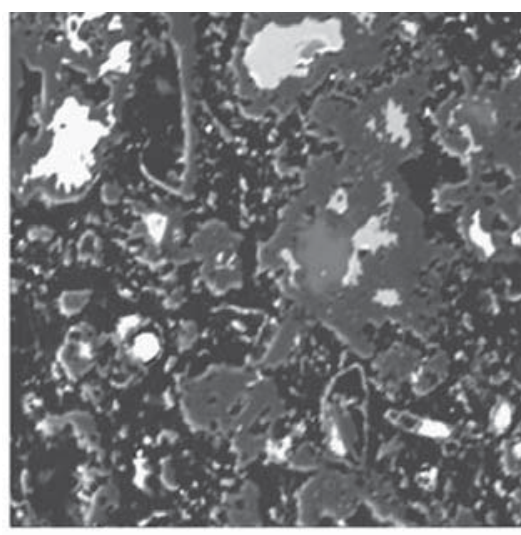

$\times 500$

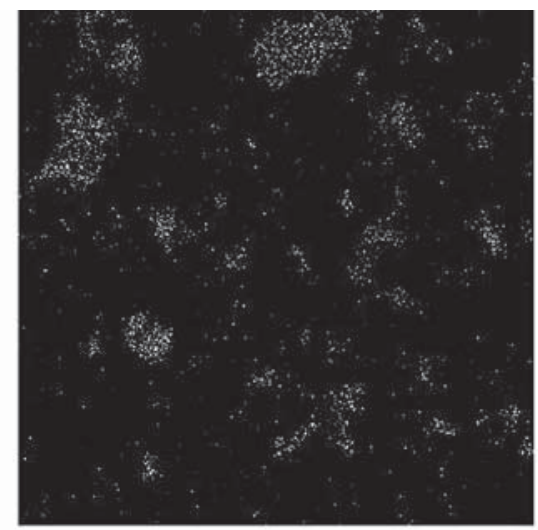

$\mathrm{Fe}$

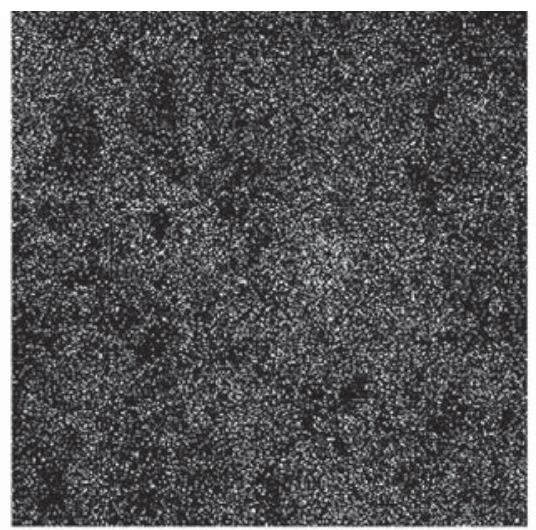

Si

Fig. 3. Nitrided cyclone dust PUD-75: Microstructure and microanalysis 
As the concentration of nitrogen goes down, so does the $\mathrm{Si}_{3} \mathrm{~N}_{4}$ concentration. The unreacted silicon can be found in the form of iron silicides. If the residual concentration of silicon is low, the product mainly contains $\mathrm{FeSi}$ and $\mathrm{Fe}_{3} \mathrm{Si}$. If the material failed to burn properly, it leads to considerable concentrations of $\mathrm{FeSi}_{2}$ and free silicon while minimizing the amount of free iron. So, by controlling the process conditions one can produce a composite material with silicon nitride as the major component (60$85 \%$ ). It will be iron that will serve as a binder in this composite at the highest nitrogen saturation degree, whereas in the case of a lower nitrogen saturation degree, it will iron silicides.

\section{Conclusion}

This paper demonstrates that the SHS technique can be used to produce a silicon nitride material from dust generated by ferrosilicium industry. The authors established certain regularities of the combustion process in the $\mathrm{FeSi}-\mathrm{N}_{2}$ system and studied the $\mathrm{SH}$ synthesis of ferrosilicium nitride. It is shown that it is possible to change the composition of the cyclone ferrosilicium dust combustion products by adjusting the nitrogen pressure and the burden dispersity. The heat-resistant $\beta$-modification of silicon nitride is at the base of such products. The most efficient applications of this form of $\mathrm{Si}_{3} \mathrm{~N}_{4}$ include refractory materials for tap holes and chutes, as well as alloying materials. Almost all of the widely used grades of ferrosilicium were used in the SHS process realized in the ( $\mathrm{Fe}-\mathrm{Si})-\mathrm{N}_{2}$ system. The PUD-75 alloy would best be used for the production of refractories, while the PUD-65 alloy would find its optimum application in steel alloying.

\section{REFERENCES}

1. Pavlov S. V., Snitko Yu. P., Plyukhin S. B. Wastes and emissions in production of ferrosilicon. Elektrometallurgiya. 2001. No. 4. pp. 22-28.

2. Gasik M. I. Problems of dispersion of high-percentage ferrosilicon with formation of toxic poisons. Stal. 1996. Vol. 38. No. 8. pp. 26-30.

3. Gasik M. I., Zubov V. L. Structural Components and Precipitated Excess Phases in 75\% Ferrosilicon Ingots. Steel in Translation. 2000. Vol. 30. No. 9. pp. 19-25.

4. Kashcheev I. D. The properties and application of refractories. Reference book. Moscow : Teplotekhnik, 2004. 352 p.

5. Vlasova M. V., Lavrenko V. A., Dyubova L. D., Tomila T. V., Isayeva L. P., Smirnov V. P. Investigation of Fine-Dispersion Silicon Nitride and Oxinitride Powders Manufactured by Titanium-Magnesium Production Waste Nitriding. Journal of Materials Synthesis and Processing. 1999. Vol. 7. No. 3. pp. 151-157.

6. Miyamoto Y., Kanehira S., Hirota K., Yamaguchi O. Development of Recycling Process for Industrial Wastes by SHS. International Journal of Self-Propagating High-Temperature Synthesis. 2000. Vol. 9, No. 3. pp. 357-362.
7. Miyamoto Y., Kanehira S., Radwan M. Recycling of Industrial Wastes to SiAlONs. Refractories Applications and News. 2004. Vol. 9. No. 1. pp. 14-17.

8. Kometani K., Lizuka K., Kaga T. Behavior of Ferro- $\mathrm{Si}_{3} \mathrm{~N}_{4}$ in Blast Furnace Tap Hole Mud. Taikabutsu. 1998. Vol. 50, No. 6. pp. 326-330.

9. Lopes A. B. The Influence of Ferro Silicon Nitride on the Performance of the Modern Taphole Mud for Blast Furnace. Refractories Applications and News. 2002. Vol. 7. No. 5. pp. 26-30.

10. Senichev G. S., Takhautdinov R. S., Badaev Y. A., Nosov A. D., Kutishev A. V., Bessmertnikh A.C. Improving the technology of smelting transformer steel in the BOF shop of OJSC MMK. Stal. 2006. No. 3. pp. 17-22.

11. Kaputkina L. M., Svyazhin A. G. High Nitrogen Steels with special functional properties. CIS Iron and Steel Review. 2014. Vol. 9. pp. 19-25.

12. Tonseth S. Dusty by product yield hard cash. GEMINI. 1998. No. 1. pp. 1-4.

13. Mukasyan A. S., Merzhanov A. G., Martynenko V. M., Borovinskaya I. P., Blinov M. Yu. Mechanism and principles of silicon combustion in nitrogen. Fizika goreniya i vzryva. 1986. No. 5. pp. 43-49.

14. Mukasyan A. S., Stepanov B. V., Galchenko Yu. A., Borovinskaya I. P. On the structure of silicon nitride formed during silicon combustion in nitrogen. Fizika goreniya i vzryva. 1990. No. 1. pp. 45-52.

15. Hirao K., Miyamoto Y., Koizumi M. Combustion reaction characteristics in the nitridation of the silicon. Advanced Ceramic Materials. 1986. Vol. 2. No. 4. pp. 780-785.

16. Ziatdinov M. Kh., Shatokhin I. M. Self-Propagating HighTemperature Synthesis of Ferrosilicon Nitride. Steel in Translation. 2008. Vol. 38. No. 1. pp. 39-44.

17. Martirosyan V. A., Sasuntsyan M. E., Saakyan N. G., Frangulyan A. A. Production of iron and silicon-doped max phases by self-propagating high-temperature synthesis. CIS Iron and Steel Review. 2019. Vol. 18. No. 2. pp. 58-63. DOI: 10.17580/ cisisr.2019.02.12.

18. Ziatdinov M. Kh., Shatokhin I. M., Leontiev L. I. SHS Technology for Composite Ferroalloys. 6. Nitrides of Ferrosilicon and Boride of Ferrotitanium. Steel in Translation. 2018. Vol. 50. No. 7. pp. 269-276.

19. Ziatdinov M. Kh., Zhukov A. S., Promakhov V. V. Combustion Synthesis of Composition Ferroalloys. Materials. 2018. 11(11):2117.

20. Levashov E. A., Mukasyan A. S., Rogachev A. S., Shtansky D. V. Self-propagating high-temperature synthesis of advanced materials and coatings. International Materials Reviews. 2017. Vol. 62. No. 4. pp. 203-239.

21. Polyushko V. A., Biryukov Yu. A., Ivonin I. V., Obiedkov A. Yu. Obtaining aluminium nitride powders by air circulation and determining their important characteristics. Izvestiya vuzov. Poroshkovaya metallurgiya i funktsionalnye pokrytiya. 2016. No. 1. pp. 12-19. 